\title{
SYSTEMATIC REVIEW: FACTORS ASSOCIATED WITH IMPLEMENTATION OF HEALTH INFORMATION MANAGEMENT IN COMMUNITY HEALTH CENTERS
}

\author{
Sri Umiati
}

Masters Program in Public Health, Universitas Sebelas Maret

\begin{abstract}
Background: Community health center (puskesmas) management information system or often referred to as SIMPUS is a local health system aimed at providing health information at primary health care level. This health information systems have been implemented in many districts. However, their performance is yet to be improved caused by several factors such as a lack of human resources and hardware. This study aimed to investigate factors associated with implementation of health information management in community health centers.

Subjects and Method: This was a systematic review by collecting published articles in openaccess journals and proceedings from Directory of Open Access Journal, Elsevier, and Google scholar databases. "Health information system", "implementation health information system", and "evaluation health information system" were used as key findings. The selected articles were reviewed by meta-aggregate.

Results: Previous studies reported that implementation of health information management in community health center faced several barriers, including (1) incomplete data, and (2) low monitoring and safety control. To implement health information management properly, the following components need to be fulfilled: (1) infrastructure availability (software, hardware, data safety, and internet network speed), (2) human source (user knowledge, experience, skill, accuracy), and (3) funds.

Conclusion: Implementation of health information management in community health center is affected by infrastructure availability, internet network speed, user knowledge and experience, and funds.
\end{abstract}

Keywords: health information management, community health center

\section{Correspondence:}

Sri Umiati. Masters Program in Public Health, Universitas Sebelas Maret. Jl. Ir. Sutami 36A, Surakarta, Central Java. Email: umi2374@gmail.com.

The $7^{\text {th }}$ International Conference on Public Health Solo, Indonesia, November 18-19, 2020 | 363 https://doi.org/10.26911/the7thicph.04.48 